\title{
O desenvolvimento humano no Espírito Santo nos anos 90: uma análise através do Índice de Desenvolvimento Humano Municipal Ajustado (IDHMA)
}

Claudeci Pereira Neto ${ }^{1}$

\begin{abstract}
Resumo
O artigo analisa o desenvolvimento humano dos municípios do estado do Espírito Santo nos anos 1990, através de alterações metodológicas na forma como se apurava o Índice de Desenvolvimento Humano Municipal (IDHM) até 2013. O novo indicador, que altera as dimensões longevidade e renda, denomina-se Índice de Desenvolvimento Humano Municipal Ajustado (IDHMA). Este indicava que no ano 2000 grande parte dos municípios capixabas enquadrava-se na faixa de médio desenvolvimento humano, e nenhum se encontrava na categoria de alto desenvolvimento. A região Norte possuía os piores indicadores de desenvolvimento em razão de suas especificidades socioeconômicas históricas. A maioria dos municípios com melhor IDHMA estava próximo a Colatina, Cachoeiro de Itapemirim e numa faixa litorânea que partia de Aracruz até Piúma.
\end{abstract}

Palavras-chave: IDHM. Índice de Gini. Espírito Santo.

\begin{abstract}
The article analyzes the human development of the municipalities of the state of Espirito Santo in the 1990s, through methodological changes in how to calculate the Municipal Human Development Index (MHDI) by 2013. The new indicator, which changes the dimensions of longevity and income, is called the Adjusted Municipal Human Development Index (AMHDI). This indicated that in the year 2000, a large part of the municipalities Capixabas was in the middle of high human development, and none of them were in the high development category. In the North region had the worse indicator development in reason its historical socioeconomic specificities. The majority of the municipalities with the better IDHMA were next to the Colatina, Cachoeiro de Itapemirim, and on the coast line from Aracruz until Piúma.
\end{abstract}

Keywords: IDH. Gini Index. Espírito Santo.

\section{Introdução}

O Índice de Desenvolvimento Humano (IDH), criado em 1990, surgiu do esforço de construção de um indicador síntese para os países e estados, capaz de substituir o tão usado PIB per capita. A partir do estabelecimento do IDH fomentou-se a criação de uma gama de indicadores com objetivo de medir o desenvolvimento de determinada área social e as diferenças de gênero. Como exemplo, pode-se citar o Índice de Desenvolvimento Ajustado ao Gênero (IDG), o Índice de Pobreza Humana (IPH) e o Índice de Desenvolvimento da Família (IDF). Esses indicadores além de fontes para pesquisas acadêmicas e informações ao público, são de suma importância aos gestores, no sentido de planejar e focalizar melhor as políticas públicas. Além disso, os indicadores servem para acompanhar a evolução dessas políticas. Um exemplo disso é o Índice Paulista de Responsabilidade Social (IPRS), elaborado pela Fundação Sistema Estadual de Análise de Dados (SEADE).

Por hora, foca-se nos dois indicadores do Programa das Nações Unidas para o Desenvolvimento (PNUD): o IDH e o Índice de Desenvolvimento Humano Municipal (IDHM). Em

\footnotetext{
${ }^{1}$ Bacharel e mestre em economia pela Universidade Federal do Espírito Santo (Ufes). Doutorando em Geografia pela mesma Universidade. E-mail: claudecineto@hotmail.com.
} 
2013, foi alterada a forma de apuração deste indicador ${ }^{2}$. A proposta deste artigo é embutir alterações metodológicas nas dimensões longevidade e renda no IDHM apurado até aquele ano e analisar o desenvolvimento humano no estado do Espírito Santo na década de 90. Tais contribuições servirão para ajustar melhor o Índice de Desenvolvimento Humano Municipal (IDHM) à realidade dos municípios brasileiros. Assim, foram alteradas as metodologias de dois, dos três subindicadores do IDHM: o Índice de Desenvolvimento Humano Municipal Renda (IDHM-R) e o Índice de Desenvolvimento Humano Municipal Longevidade (IDHM-L). Além disso, na dimensão renda foi inserido um componente que refletisse a concentração da renda: o Índice do Gini.

Esse novo indicador, o qual denomina-se Índice de Desenvolvimento Humano Municipal Ajustado (IDHMA), indicava, que no ano 2000, a maioria dos municípios possuía médio desenvolvimento humano. Além disso, todos os municípios da região mais ao norte do estado apresentavam médio IDHMA e os da Região Metropolitana da Grande Vitória, exceto Viana, médio-alto desenvolvimento humano.

\section{Um indicador de desenvolvimento humano dos países: o IDH}

O conceito de desenvolvimento humano torna-se muito amplo ao se analisar as diversas necessidades das pessoas e suas variações ao longo do tempo. O Programa das Nações Unidas para o Desenvolvimento (PNUD, 1996, p. 1) o define “[...] como o processo para ampliação da gama de opções e oportunidades das pessoas". Assim, o desenvolvimento humano precisa expandir as várias opções dos indivíduos, sejam econômicas, políticas, culturais, sociais e ambientais. Certamente, "o fundamento real do desenvolvimento humano é o universalismo do direito à vida" (PNUD, 1996, p.2). A busca de um desenvolvimento humano eqüitativo deve consentir a todos os indivíduos, indistintamente, cultivar suas capacidades e delas usufruir, em todos os campos da vida social.

O PNUD, anualmente, desde 1990, nos Relatórios sobre o Desenvolvimento Humano vem trazendo um indicador síntese do desenvolvimento humano, o IDH (Índice de Desenvolvimento Humano). Este foi idealizado pelo economista paquistanês Mahbub ul Haq (1934-1998), conselheiro especial do PNUD, com a colaboração do também economista indiano Amartya Sen ${ }^{3}$. Leva em consideração a existência de três condições básicas para ampliar as oportunidades do ser humano e sem as quais se tornam inacessíveis as escolhas das outras: “[...] desfrutar de uma vida longa e saudável, adquirir conhecimento e ter acesso aos recursos necessários para um padrão de vida decente" (PNUD, 1996, p.11).

O próprio Sen no início não depositava muita confiança "[...] sobre a tentativa de focalizar, em um índice bruto desse tipo - apenas um número -, a realidade complexa do desenvolvimento e da privação humanos" (Amartya Sen apud PNUD, acesso em 03 set. 2008). No entanto, a proposta do seu criador era produzir uma medida sucinta que pudesse substituir o Produto Interno Bruto (PIB) per capita, utilizado correntemente para designar e comparar o

\footnotetext{
${ }^{2}$ A nova metodologia pode ser encontrada em http://www.atlasbrasil.org.br/2013/pt/o_atlas/idhm/.

${ }^{3}$ Prêmio Nobel de Economia em 1998.
} 
desenvolvimento entre países e estados. Obviamente, o IDH, por ser uma medida sintética, "não abrange todos os aspectos de desenvolvimento e não é uma representação da 'felicidade' das pessoas, nem indica 'o melhor lugar do mundo para se viver'"' (PNUD, acesso em 03 set. 2008). No entanto, essas considerações não tiram os méritos desse índice e sua contribuição tanto acadêmica quanto para a tomada de decisões de políticas públicas.

Assim, o IDH, propõe a inclusão de três aspectos: saúde (longevidade), nível de educação e acesso à renda. "[...] os dois primeiros incorporados como valores em si mesmos e o último como um meio para os outros fins" (PNUD, 1996, p.11). "A renda é um meio, tendo como fim o desenvolvimento humano" (PNUD, 1990, apud ROLIN, 2005, p.5). O que se passa a descrever é a metodologia empregada até 2013.

A longevidade era medida pela esperança de vida ao nascer. Já o nível educacional pela média entre a taxa de alfabetização de adultos (peso 2) e a taxa combinada de matrículas nos níveis de ensino fundamental, médio e superior (peso 1). 0 acesso à renda era mensurado pelo poder de compra, de acordo com o PIB per capita ajustado ao custo de vida da região (Paridade do Poder de Compra - PPC) ${ }^{4}$. Cada sub-índice era calculado a partir de valores máximos e mínimos para cada variável examinada:

- Esperança de vida ao nascer

25 anos e 85 anos

- Alfabetização de adultos

$0 \%$ e $100 \%$

- Taxa combinada bruta de matrículas

$0 \%$ e $100 \%$

- Renda real per capita PPC $\$ 100$ e $\$ 40.000$

Dado os limites máximo e mínimo, verificava-se a situação de cada país ou estado em relação a esses valores. Pelo valor observado de cada variável em uma dada região, encontravase um índice que varia de 0 a 1, partindo de uma expressão básica:

$$
\text { Indicador }=\frac{\text { valor observado }- \text { valor mínimo }}{\text { valor máximo }- \text { valor mínimo }}
$$

Assim, tendo em mãos o valor observado da esperança de vida ao nascer $\left(l_{\mathrm{i}}\right)$ do país $i$, o indicador de longevidade $\left(L_{i}\right)$ derivava da simples aplicação da fórmula:

$$
L_{i}=\frac{l_{i}-25}{85-25}
$$

Já para a mensuração do indicador do nível educacional $\left(E_{i}\right)$ do país $i$ levava-se em consideração os diferentes pesos da taxa de alfabetização de adultos $\left(\mathrm{a}_{\mathrm{i}}\right)$ e da taxa combinada de matrícula dos níveis de ensino fundamental, médio e superior $\left(\mathrm{m}_{\mathrm{i}}\right)$. Então,

$$
E_{i}=2 \frac{\left(\mathrm{a}_{\mathrm{i}}-0\right)}{(100-0)}+1 \frac{\left(\mathrm{m}_{\mathrm{i}}-0\right)}{(100-0)}
$$

\footnotetext{
${ }^{4}$ O conceito de Paridade de Poder de Compra (PPC) foi popularizado pelo economista sueco Gustav Cassel, no início do século XX. Baseia-se na crença de que qualquer mercadoria num mercado totalmente integrado deve ter o mesmo preço em diferentes países, quando expressados em uma moeda comum. Basta a aplicação de uma taxa de câmbio para converter a moeda estrangeira em moeda nacional, e vice-versa. Essa doutrina amplia-se assim para uma cesta de mercadorias que representa o nível médio de preços na economia (D.SACHS; LARRAIN B., 2000, p.316-317).
}

COLÓQUIO - Revista do Desenvolvimento Regional - Faccat - Taquara/RS - v. 17, n. 1, jan./mar. 2020 
A fórmula do indicador de acesso a renda era um pouco diferente por levar em consideração a utilidade marginal da renda (ROLIM, 2005, p.7). “O logaritmo é usado porque ele expressa melhor o fato de que um acréscimo de renda para os mais pobres é proporcionalmente mais relevante do que para os mais ricos" (PNUD, acesso em 01 set. 2008). Ou seja, o uso desse recurso partia da ideia de que um acréscimo de $\mathrm{R} \$ 100$ na renda de quem ganha um salário mínimo gera um maior bem-estar caso esse mesmo aumento, por exemplo, também fosse concedido a uma outra pessoa que recebe 20 salários mínimos. Portanto, sendo $Y_{i}$ o PIB per capita ajustado (PPC) do país ou estado $i$, o indicador renda $\left(R_{i}\right)$ era dado pela seguinte equação logarítmica:

$$
R_{i}=\frac{\log \left(Y_{i}\right)-\log (100)}{\log (40000)-\log (100)}
$$

Todos os valores são em dólar - Paridade Poder de Compra - para garantir comparabilidade entre os países, sendo que o valor da taxa de dólar PPC é dado pelo Banco Mundial (ADHB, 2003, metodologia). São publicadas "[...] con regularidad en las ediciones anuales de Atlas de Banco Mundial y World Development Indicators" (PRB, 2001, p.9).

O cálculo do IDH vem sendo aperfeiçoado ao longo dos anos, mas a sua idéia principal continua a mesma. Até 2013, obtinha-se o IDH pela média aritmética simples dos três subindicadores: Indicador de Longevidade $\left(\mathrm{L}_{\mathrm{i}}\right)$, Indicador de Nível Educacional $\left(\mathrm{E}_{\mathrm{i}}\right)$ e Indicador de Renda $\left(\mathrm{R}_{\mathrm{i}}\right)$. Ou seja:

$$
I D H=\frac{L_{i}+E_{i}+R_{i}}{3}
$$

Assim, o IDH varia de 0 a 1, onde mais próximo de 1, maior o desenvolvimento humano do país ou região ${ }^{5}$. Convencionou-se pelo PNUD avaliar com baixo desenvolvimento humano países ou estados com IDH até 0,499; os que apresentam entre 0,5 e 0,799 são considerados de médio desenvolvimento, e os com IDH a partir de 0,8 são vistos como sendo de alto desenvolvimento humano.

\section{0 índice de desenvolvimento humano para municípios}

A formulação do Índice de Desenvolvimento Humano Municipal (IDHM) se deve às iniciativas de pesquisadores da Fundação João Pinheiro e do Instituto de Pesquisas Econômicas Aplicadas (IPEA), inicialmente para o caso dos municípios do estado de Minas Gerais, realizado em 1996 (SANTOS, 2006, p.95). Esse indicador envolve as mesmas dimensões do IDH, com algumas adaptações a núcleos sociais menores, retratando, assim, melhor a realidade dos

\footnotetext{
5 “Tais limites devem ser interpretados com cuidado. O IDH não é uma medida normativa; nesse sentido, o valor 1 não indica um valor ideal a ser alcançado, mesmo porque o processo de desenvolvimento significa exatamente a ampliação de oportunidades e opções e aponta, portanto, para a superação desses limites em relação a duas das quatro variáveis [esperança de vida e renda real per capita]. Assim, o IDH deve ser considerado mais propriamente como uma medida mínima, cujo significado, de certa forma, se reduz para os países nos quais o índice alcança um valor elevado; nesses países, a ênfase tende a se deslocar para outra dimensão do desenvolvimento humano" (PNUD, 1996, p.11-12).
} 
municípios. Além disso, a base de dados é obtida diretamente dos Censos Demográficos, o que facilita a construção dos índices.

Algumas alterações foram realizadas no que tange à escolha dos dados para a formação do indicador de renda e nível educacional. Até 2013, o cálculo do indicador de longevidade, que denominaram Índice de Desenvolvimento Humano Municipal Longevidade (IDHM-L), continuou com a mesma configuração proposta pelo IDH, ou seja, baseado nos dados de esperança de vida ao nascer e com mesmos limites inferior ( 25 anos) e superior ( 85 anos).

O cálculo da esperança de vida ao nascer é complexo e envolve várias fases. No caso da esperança de vida por município, as estatísticas do registro civil são inadequadas. Por isso, para o cálculo do IDH municipal optou-se por técnicas indiretas para se chegar às estimativas de mortalidade. A base são as perguntas do Censo sobre o número de filhos nascidos vivos e o número de filhos ainda vivos na data em que o Censo foi feito. A partir daí são calculadas proporções de óbitos. Aplica-se, então, uma equação que transforma essas proporções em probabilidade de morte. A próxima etapa é transformar essas probabilidades em tábuas de vida, de onde é extraída a esperança de vida ao nascer (PNUD, acesso em 01 set. 2008).

Na dimensão educação foi substituída a taxa combinada de matrículas, do IDH, pela taxa bruta de freqüência escolar, medida pela divisão dos alunos nos três níveis de ensino pela população de 7 a 22 anos do município. De acordo com o Ministério da Educação essa seria a idade que uma pessoa estaria envolvida no ciclo de aprendizado, desde o ensino fundamental ao fim do ensino superior. Quando se trata de regiões menores, a taxa bruta de matrícula pode causar distorções, pois alunos podem residir em uma cidade e estudar em outra; por isso, a adoção da taxa de freqüência à escola, a qual retrata a população daquele município que vai à escola em comparação à população em idade escolar (PNUD, acesso em 01 set. 2008).

Além disso, calcula-se a taxa de alfabetização pela razão dos alfabetizados (pessoas capazes de ler e escrever um bilhete simples) maiores de 15 anos e a população do município também nessa faixa etária. Essa opção está em consonância com a idéia de que o estudo normal das séries do ensino fundamental se encerra aos 14 anos (PNUD, acesso em 01 set. 2008).

Na construção do Índice de Desenvolvimento Humano Municipal Educação (IDHM-E), a taxa bruta de frequência escolar $\left(e_{i}\right)$, de certo município $i$, tinha peso um e a taxa de alfabetização $\left(b_{i}\right)$, peso dois. Como essas duas taxas variam entre 0 e 1 , torna-se desnecessário transformar num índice, como na dimensão educação do IDH, basta apenas aplicar os pesos de cada taxa.

$$
I D H M-E=\frac{e_{i}+2\left(b_{i}\right)}{3}
$$

No que diz respeito à renda os limites inferiores e superiores eram os mesmos adotados pelo PNUD para o cálculo do IDH dos países, isto é, US\$ PPC 100 e US\$ PPC 40.000. Todavia, esses valores-limites foram "[...] convertidos a valores de renda per capita mensal em reais através da multiplicação pelo fator (R\$297 / US\$ 7.625 PPC), que é a relação entre a renda per capita mensal (em reais) e o PIB per capita anual (em dólares PPC) do Brasil em 2000" (PNUD, acesso em 03 set. 2008). Desse modo, foram obtidos os limites inferior $(R \$ 3,90)$ e superior $(R \$ 1.559,24)$. Para se calcular o Índice de Desenvolvimento Humano Municipal Renda (IDHM-R) do Censo de 1991, os 
rendimentos de sua data de referência (10 de setembro) tiveram que ser inflacionados pelo Índice Nacional de Preços ao Consumidor (INPC), do Instituto Brasileiro de Geografia e Estatística (IBGE), para a data de referência do Censo Demográfico de 2000 (10 de agosto) (ADHB, 2003, metodologia).

Somado a isso, o PIB per capita ${ }^{6}$ foi substituído pela renda familiar per capita média municipal, encontrada pelo somatório da renda de todos os residentes do município (salários, pensões, aposentadorias, transferências governamentais etc.) dividido pelo número de pessoas que nele reside, inclusive crianças e pessoas com nenhuma renda (PNUD, acesso em 01 set. 2008).

No caso brasileiro, o cálculo da renda municipal per capita é feito a partir das respostas ao questionário expandido do Censo - um questionário mais detalhado do que o universal e que é aplicado a uma amostra dos domicílios visitados pelos recenseadores. Os dados colhidos pelo Instituto Brasileiro de Geografia a Estatística (IBGE) através dessa amostra do Censo são expandidos para o total da população municipal e, então, usados apara o cálculo da dimensão renda do IDHM (PNUD, acesso em 01 set. 2008).

Como no cálculo do IDH, lança-se mão da mesma equação logarítmica. Entretanto o PIB per capita foi substituído pela renda média per capita municipal $\left(r_{i}\right)$. Sendo assim, a equação do Índice de Desenvolvimento Humano Municipal Renda (IDHM-R) estrutura-se desse modo:

$$
I D H M-R=\frac{\log \left(r_{i}\right)-\log (3,90)}{\log (1559,24)-\log (3,90)}
$$

A partir da média simples desses três indicadores, até 2013, forma-se o IDHM, o qual tende a reproduzir melhor o estágio de desenvolvimento humano municipal. Este, como não podia deixar de ser, também varia entre 0 a 1 . Quanto mais próximo da unidade, maior 0 desenvolvimento humano do município analisado.

$$
I D H M=\frac{I D H M-L+I D H M-E+I D H M-R}{3}
$$

Para melhor entendimento, o PNUD classificava as faixas do IDHM em cinco categorias:
$0,000-0,299$ Baixo desenvolvimento humano
$0,300-0,499$-------- Baixo-médio desenvolvimento humano
0,500 - 0,649 --------- Médio desenvolvimento humano
$0,650-0,799$--------- Médio alto desenvolvimento humano
$0,800-1,000$--------- Alto desenvolvimento humano

\footnotetext{
${ }^{6}$ A pouca adequação do PIB per capita como fonte de dados para os municípios está, por exemplo, na observação de que nem toda a renda produzida nos limites geográficos de cada cidade é apropriada pela população residente. 


\section{Uma Contribuição ao IDHM para adequá-lo à realidade brasileira}

A dimensão continental brasileira e suas discrepâncias regionais: econômicas, populacionais, sociais etc., ratificam o jargão de "vários brasis dentro do Brasil". Ao vislumbrar tais fatos, achou-se por bem empreitar uma tentativa de ajustar o IDHM à realidade brasileira. Dos três sub-índices que compõe o IDHM, optou-se por modificar apenas dois: o IDHM-L e o IDHM-R. Para o IDHM-E seguiu-se a mesma proposta metodológica do PNUD. Além disso, foi acrescido o índice de Gini para incorporar no indicador o fator concentração de renda.

O problema contemplado no IDHM-L foram os valores-limites para a esperança de vida ao nascer (sexos reunidos), os quais foram tomados, sem nenhuma alteração do IDH, ou seja, 25 anos para o valor inferior e 85 anos para o superior. Com isso, o limite inferior permaneceu muito desatualizado, haja vista que em nenhum país do mundo, no final do século XX, a esperança de vida se encontrava abaixo de 30 anos. Aliás, em 2000, o Zâmbia, país do Continente Africano, possuía a menor esperança de vida (33 anos). Por outro lado, o limite superior estava um pouco acima da melhor esperança de vida mundial para aquele ano (81 anos), atribuída ao Japão (PRB, 2001).

Assim, adotou-se, para o novo IDHM-L, como valores-limites a pior e a melhor expectativa de vida dentre os municípios do território brasileiro. Dessa forma, de acordo com informações do Atlas de Desenvolvimento Humano no Brasil (ADHB, 2003), em 1991, o parâmetro de longevidade mínimo do Brasil foi 50,24 anos, que correspondia a esperança de vida do município de Santa Filomena do Maranhão (MA), e o parâmetro máximo, 74,6 anos, referente ao município de Morro Reuter (RS). Já para o ano de 2000, Centro Guilherme, no estado do Maranhão, possuía a pior esperança de vida dentre os municípios do país (54,35 anos), enquanto São Caetano do Sul, no estado paulista, a melhor (78,18 anos).

Considerando as informações do ADHB (2003) sobre a esperança de vida ao nascimento $\left(l_{i}\right)$ de cada município $(i)$, aplica-se a mesma fórmula do IDHM, com o cuidado de inserir os parâmetros de longevidade $(P)$, para os anos $(j)$ de 1991 e 2000, como já expostos:

$$
I D H M-L=\frac{l_{i}+P_{j \min }}{P_{j \max }-P_{j \min }}
$$

Em relação ao IDHM-R foram realizadas duas mudanças metodológicas. A primeira diz respeito a utilização do rendimento nominal mensal familiar per capita, ou seja, a soma dos rendimentos dos componentes da família dividida pelo número de seus componentes, exclusive os pensionistas e os empregados domésticos (IBGE, 1996, p.45). Esses dados foram extraídos diretamente do Censo Demográfico e fornecidos pelo IBGE. O sitio deste Instituto contém as tabelas com as informações dos dois Censos. Para 1991, utilizou-se a tabela 6.24 retirada da Biblioteca Virtual; já para 2000, a tabela 238, extraída do Banco de Dados Agregados. Nas colunas dessas tabelas localizam-se as classes de rendimento fracionadas por salários mínimos. Essas 
classes iniciam com famílias com nenhum rendimento médio mensal familiar per capita até aquelas nas quais cada componente recebe mais de 10 salários mínimos.

Para a classe de rendimento salarial familiar per capita de mais de 10 salários mínimos estabeleceu-se um ponto médio de classe igual a 15 salários mínimos. Cabe ainda ressaltar que, para o Censo de 1991, a coluna "sem declaração" foi excluída do cálculo. A classificação "sem declaração de rendimento" aplicou-se não somente as pessoas que não responderam aos quesitos específicos, mas também àquelas cujas informações sobre as demais características econômicas indicavam existência de rendimentos (IBGE, 1996, p.40).

O Censos de 1991 teve como data de referência 10 de setembro; já o de 2000, 1ㅇ de agosto. Os salários mínimos vigentes nessas duas datas eram $\mathrm{Cr} \$ 36.161 .60$ e $\mathrm{R} \$ 151,00$, respectivamente. Ao se buscar uma comparação desses dois períodos optou-se por corrigir o valor do salário mínimo para a data de referência do Censo 2000. Para isso, empregou-se como deflator o Índice de Preços ao Consumidor Amplo (IPCA), o qual considera "[...] a variação dos preços das cestas de consumo das famílias com recebimento mensal de 1 a 40 salários mínimos, qualquer que seja a fonte" (IBGE, acesso em 5 abr. 2008). Esse índice de preços mensurava as variações nas cidades de Brasília e Goiânia, além de 9 regiões metropolitanas: Belém, Fortaleza, Recife, Salvador, Belo Horizonte, Rio de Janeiro, São Paulo, Curitiba e Porto Alegre. Apesar do IPCA, não medir as variações de preços no interior do país e muito menos em qualquer região do estado do Espírito Santo, optou-se por adotá-lo, uma vez que ele reflete melhor o universo salarial de rendimentos das famílias.

Uma vez escolhido o deflator, recorreu-se ao sitio do Banco Central do Brasil para a correção dos valores levando em conta a reforma monetária ocorrida em primeiro de julho de 1994, a qual mudou a unidade monetária de Cruzeiro para Real. O resultado da correção apontou que o salário de 1991 correspondia a $\mathrm{R} \$ 145,95$ em 1 o de agosto de 2000, um pouco menor do que o vigente, $R \$ 151,00$ (BCB, acesso em 6 nov. 2017).

Desse modo, para se calcular o rendimento médio mensal familiar per capita $(R f)$ do município ( $i$ ) lançou-se mão de uma média aritmética ponderada simples:

$$
R f_{i}=\left(\frac{\sum x . b}{\sum b}\right) \cdot S_{j}
$$

Onde,

$x=$ pontos médios das classes de rendimento salarial familiar per capita;

$b=$ número de famílias em cada classe de rendimento salarial familiar per capita;

$S_{j}=$ valor do salário mínimo nos anos ( $j$ ) 1991 e 2000, sendo naquele ano corrigido para a data de referência do Censo 2000.

A segunda mudança trata-se de substituir os limites inferiores e superiores para a renda, sugeridos pelo PNUD em dólar PPC e convertidos para o Brasil nos valores de $\mathrm{R} \$ 3,90$ e $\mathrm{R} \$$ $1.559,24$. Essa alteração consistiu em adotar como valores-limites os pontos médios da primeira e da última classe de rendimento médio mensal familiar per capita. Partindo dessa idéia, o ponto médio da primeira classe com rendimento (de 0 a $1 / 8$ de salário mínimo) é 0,0625 do salário 
mínimo; já o da última classe de rendimento familiar per capita (mais de 10 salários mínimos) convencionou-se como ponto médio 15 salários mínimos.

O próximo passo foi a conversão desses valores-limites, por faixas de salários mínimos, para valores monetários correntes, ou seja, para Reais. Tomando o salário mínimo vigente na data de referência do Censo 2000 ( $R \$ 151,00$ ) encontrou-se os limites para esse ano: $R \$ 9,44$ e $\mathrm{R} \$ 2.265,00$, multiplicando os pontos médios pelo salário vigente. Esses valores também foram empregados para os dados de 1991, haja vista que as classes de rendimento salarial para este ano foram deflacionadas para a data de referência do Censo Demográfico 2000.

Assim, para o novo cálculo do Índice de Desenvolvimento Humano Municipal Renda (IDHM-R), além dos valores-limites para a renda, leva-se em consideração o rendimento médio mensal familiar per capita ( $R f$ ) do município ( $i$ ) nos anos $(k)$ de 1991 e 2000:

$$
I D H M-R=\frac{\log \left(R f_{i k}\right)-\log (9,44)}{\log (2265)-\log (9,44)}
$$

Somado a isso, incorporou-se na dimensão renda outro componente: a distribuição de renda. Como $R f$ é uma média e, por isso, traz limitações no que diz respeito ao quesito distribuição, necessário se faz a inclusão de um indicador que reflita as disparidades de rendimentos.

É sabido, de longa data, que o Brasil caracteriza-se por ter uma das piores distribuições de renda do mundo. Alguns dados para o início do século XXI estão expostos na Tabela 1. A desigualdade chega a níveis alarmantes e desafiadores: $1 \%$ da população mais rica se apropriava de maior proporção da renda domiciliar brasileira $(13,90)$ do que os $50 \%$ mais pobres (apenas 12,58\%). E ainda, os rendimentos médios de $10 \%$ dos indivíduos mais ricos do país superavam em mais de 23 vezes o rendimento médio de $40 \%$ da população mais pobre.

Ao se examinar os dados pelas Regiões do país observa-se, no ano 2001, uma maior concentração da renda no Centro-oeste e Nordeste. Nesta Região, 16,2\% da renda domiciliar per capita é apropriada por $1 \%$ da população mais rica; enquanto $50 \%$ das pessoas mais pobres participam com apenas $13,04 \%$ da renda. A Região Sul, apesar da enorme concentração, comparativamente, destaca-se por melhor distribuir sua renda: $15,38 \%$ da sua renda total vai para as mãos dos $50 \%$ dos indivíduos mais pobres, e $12,35 \%$ para os $1 \%$ mais ricos. 
Tabela 1 - Participação de estratos da população brasileira na renda domiciliar per capita e Índice de Gini (2001)

\begin{tabular}{l|c|c|l|c}
\hline \hline País/região/estado & $\begin{array}{l}\text { Participação (\%) } \\
\text { dos 1\% mais ricos }\end{array}$ & $\begin{array}{l}\text { Participação (\%) } \\
\text { dos 50\% mais } \\
\text { pobres }\end{array}$ & $\begin{array}{l}\text { Razão entre a renda dos } \\
10 \% \text { mais ricos e 40\% } \\
\text { mais pobres }\end{array}$ & Índice de Gini \\
\hline \hline Brasil & 13,90 & 12,58 & 23,34 & 0,596 \\
Regiões & 14,16 & 14,68 & 18,50 & 0,565 \\
Norte & 16,20 & 13,04 & 22,92 & 0,600 \\
Nordeste & 14,56 & 13,12 & 22,35 & 0,598 \\
Centro-Oeste & 12,60 & 14,13 & 19,20 & 0,568 \\
Sudeste & 12,35 & 15,38 & 17,01 & 0,548 \\
Sul & 13,95 & 12,76 & 22,63 & 0,594 \\
Espírito Santo & & & & 0 \\
\hline \hline
\end{tabular}

Fonte: elaboração própria a partir dos dados do IPEA.

No estado do Espírito Santo a participação da renda dos $1 \%$ mais ricos e dos $50 \%$ mais pobres estão próximos à média nacional. Entretanto, observa-se que o estado capixaba apresenta piores números quando comparados com a média da Região Sudeste e até mesmo, em alguns casos, com outras Regiões. No Espírito Santo, 1\% pessoas mais ricas se apropriavam de 13,95\% da renda domiciliar per capita, acima da média dos estados do Sudeste $(12,6 \%)$. Já a participação dos $50 \%$ mais pobres capixabas $(12,76 \%)$ era inferior à média de cada Região do país. E ainda, a renda domiciliar de $10 \%$ dos indivíduos mais ricos do estado superava em 22,63 vezes o rendimento médio de $40 \%$ da população mais pobre; essa relação só era menor que a média dos estados da Região Nordeste (22,92).

Assim, para incluir na dimensão renda um indicador que refletisse as discrepâncias de distribuição optou-se pelo conhecido Índice de Gini ${ }^{7}$. O Índice de Gini ( $G$ ) pode ser medido pela fórmula (SANDRONI, 2005, p.156):

$$
G=1-\sum_{i=1}^{n}\left(Y_{i}+Y_{i-1}\right)\left(X_{i}-X_{i-1}\right)
$$

Sendo,

$X_{i}=$ a porcentagem acumulada das famílias até o estrato de rendimento $i$;

$Y_{i}=$ a porcentagem acumulada da renda até o estrado $i$;

$n=$ número de estratos de renda.

Como não podia deixar de ser, o valor desse indicador varia entre 0 e 1 . O coeficiente zero corresponde à perfeita igualdade de renda (onde todos têm a mesma renda) e 1 à completa desigualdade (onde uma pessoa detém toda renda).

\footnotetext{
7 O Índice de Gini é uma medida de desigualdade desenvolvida pelo estatístico italiano Corrado Gini, no ínício do século XX (SANDRONI, 2005, p.375). O PNUD, no Atlas de Desenvolvimento Humano no Brasil (ADHB), disponibiliza para os anos de 1991 e 2000 esse indicador para todos os municípios do país.
} 
Ao final da apresentação das modicicações na metodologia do IDHM-L e IDHM-R, e a justificativa da inclusão do Índice de Gini na mensuração, resta-nos formalizar a equação geral para se chegar ao novo IDHM, no qual denomina-se Índice de Desenvolvimento Humano Municipal Ajustado (IDHMA):

$$
I D H M A=\frac{\frac{I D H M-R+(1-G)}{2}+I D H M-L+I D H M-E}{3}
$$

Além de também variar entre 0 e 1 , assim como o IDHM, atribui pesos iguais as três dimensões: saúde, educação e renda. Na dimensão renda acrescentou-se o Índice de Gini (G) subtraído da unidade. Isso se explica por este indicador guardar uma relação inversa em relação aos demais expostos na fórmula do IDHMA. Isto é, ao contrário do IDHM-R, do IDHM-L e do IDHM-E, o Índice de Gini, ao se aproximar da unidade reflete uma piora no indicador, ou seja, na distribuição de renda.

\section{Resultado nas alterações no IDHM-L e no IDMH-R}

Em 1991 o estado possuía 67 municípios. Na década de 90 foram criados mais 10 municípios. Para efeito de comparação entre o início e o final dos anos 90, optou-se por usar a base cartográfica do ano 2000, com 77 municípios. Nos mapas de 1991 foram incluídas essas novas unidades. Isso só foi possível porque o PNUD, no Atlas de Desenvolvimento Humano no Brasil, disponibiliza, para 1991, dados desses novos municípios desagregados dos municípios de origem. Cabe ressaltar que para o cálculo do Índice de Desenvolvimento Humano Municipal Renda e do Índice de Gini, para os municípios emancipados pós Censo de 1991, lançou-se mão dos mesmos números dos municípios de origem.

A análise da dimensão saúde (longevidade) se dá pela esperança de vida ao nascer, tendo como valores limites a melhor e a pior esperança de vida dentre os municípios brasileiros, assim como exposto na primeira parte deste capítulo. Os resultados para os municípios do Espírito Santo podem ser vistos no Mapa 1.

Em 1991, destacam-se os municípios de Pedro Canário e Conceição da Barra, os únicos a apresentarem baixo Índice de Desenvolvimento Humano Municipal Longevidade, e Santa Teresa o único a se enquadrar na categoria de alto desenvolvimento. Cabe lembrar também que o município de Cariacica em 1991, era o único da Grande Vitória a apresentar IDHM-L na faixa baixo-médio.

No final da década, o Espírito Santo apresentava na faixa médio IDHM-L, a mesma quantidade de municípios registrados em 1991. Em 2000, nenhuma cidade estava na categoria de baixo desenvolvimento, e Iconha e Rio Novo do Sul passaram para a faixa de alto IDHM-L. O destaque para o ano de 2000 foi a piora do índice em trinta municípios, fazendo com que sete deles mudassem classe: Nova Venécia, João Neiva, Vila Velha e Apiacá passaram da categoria médio-alto para médio; já Vila Pavão, Jerônimo Monteiro e Muqui, da médio para baixo-médio. 
A explicação para esse fato está na constatação de que embora todos os municípios do estado tenham melhorado suas esperanças de vidas, eles não conseguiram acompanhar a evolução dos limites inferiores e superiores da esperança de vida brasileira, ou seja, da pior e da melhor expectativa de vida dentre os municípios do Brasil. Se a cada mensuração a esperança de vida do municio não acompanhar proporcionalmente esses valores limites verá seu IDHM-L se reduzir.

Aliás, em 2000, na Região Metropolitana de Vitória, a qual compõe parte expressiva da população do estado, somente a Capital e Guarapari possuíam indicadores médio-alto; os demais apenas médio.

Destacam-se os municípios mais ao Norte e Noroeste do estado com os piores indicadores, isto é, na categoria baixo-médio. Contribuem para esse quadro a pouca atenção à saúde pública e fatores econômicos, como, por exemplo, a baixa renda familiar e o fraco dinamismo econômico daquelas regiões.

Mapa 1 - Índice de Desenvolvimento Humano Municipal Longevidade (IDHM-L) dos municípios capixabas - 1991 e 2000

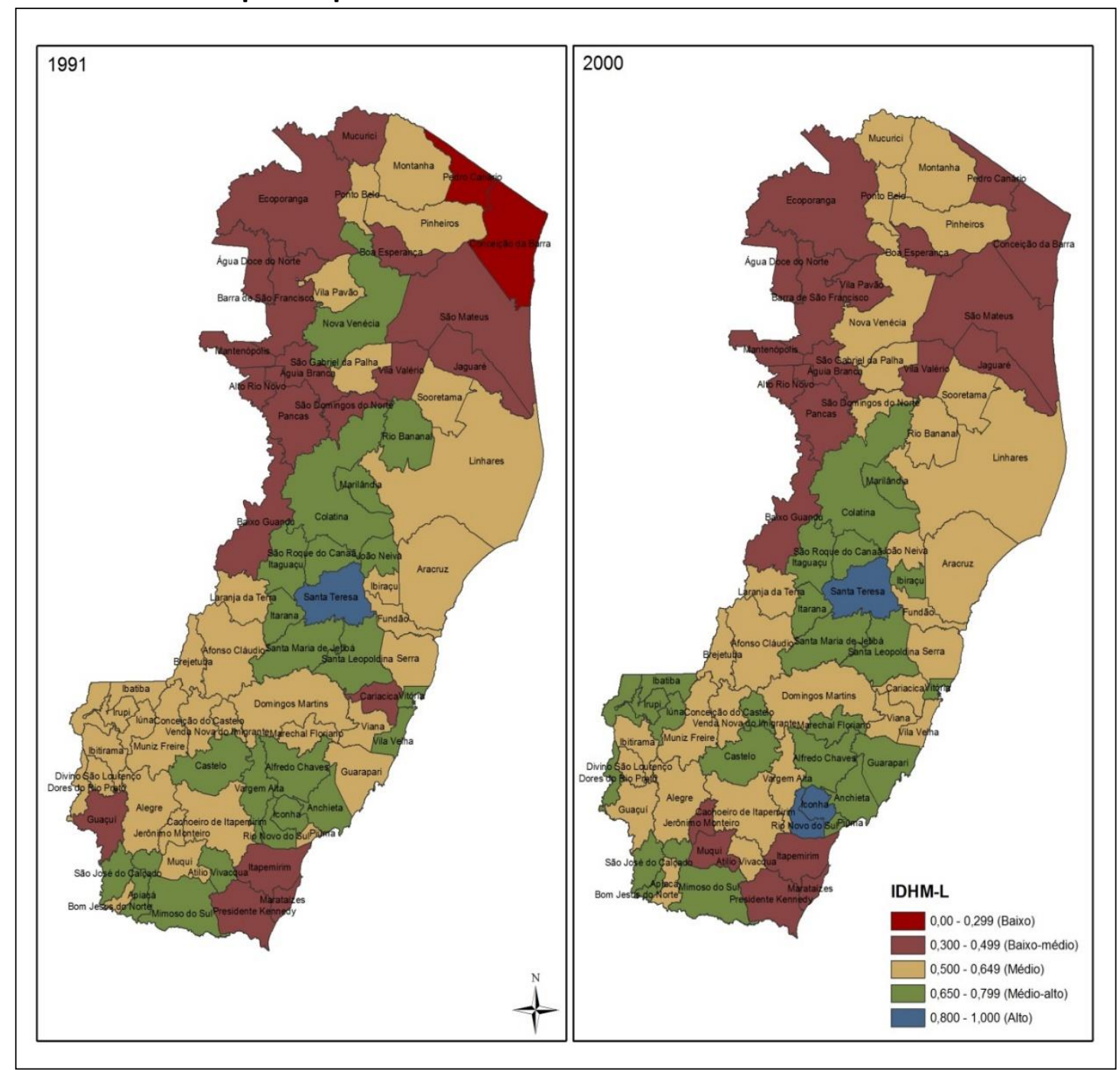

Fonte: Elaborado com dados publicados pelo PNUD (ADHB). 
Na construção do IDHM-R apurou-se conforme a nova metodologia apresentada. Os resultados comparativos dos anos 1991 e 2000 estão no Mapa 2. Nele verifica-se que nenhum município capixaba possuía o IDHM-R alto. Além disso, o indicador da maioria situava-se na faixa baixo-médio. Nota-se também o reduzido número de municípios que melhoraram de faixa no indicador. Nesse aspecto, somente as unidades de Anchieta (no litoral sul), e as de João Neiva, Linhares, Sooretama, Jaguaré e Pedro Canário, obtiveram avanço. A capital do estado foi a única a apresentar $o$ indicador médio-alto nos dois períodos analisados.

Atenta-se para o fato de que um corredor de municípios mais interiorizados e limítrofes com Minas Gerais possuía os piores índices de IDHM-R. Esse corredor foi somente estreitado próximo à Colatina, cidade regional estratégica e importante entreposto para os municípios ao seu entorno. Esta se destaca pelo contingente populacional, nível de urbanização da população e por ter um rendimento médio salarial familiar per capita bem acima dos municípios daquele corredor.

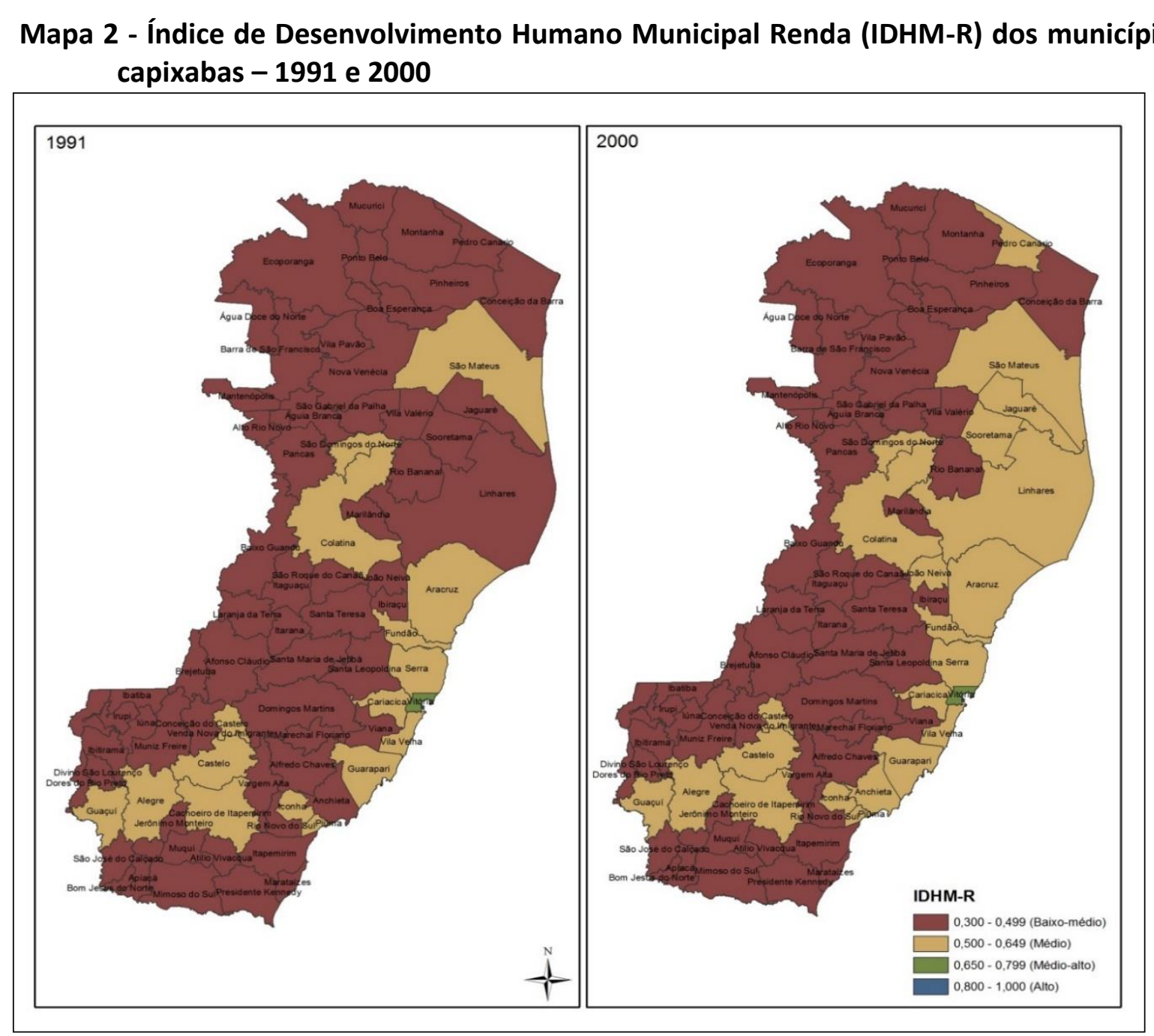

Fonte: Elaborado com dados publicados pelo IBGE.

Apesar do Rendimento médio salarial familiar per capita ter melhorado em todos os municípios, a concentração dos rendimentos nos municípios do Espírito Santo tendeu 
a ficar mais distribuído no território entre os dois Censos, conforme as categorias atribuídas pelo PNUD a esse indicador. Tal tendência pode ser observada através do Índice de Gini, retratado no Mapa 3.

Ao se considerar a variação decimal e centesimal no Índice de Gini, constata-se que 35 municípios tiveram variações positivas entre os dois Censos analisados; isto é, aumentaram a concentração da renda. Nesses municípios viviam 73,57\% da população do Espírito Santo. Com exceção de Fundão, todos os municípios da Região Metropolitana da Grande Vitória, onde residia grande parte da população capixaba, viu seu grau de concentração de renda se elevar. Cidades populosas e estratégicas economicamente, como Aracruz, Colatina, Linhares e São Mateus, também estavam nessa lista.

Mapa 3 - Índice de Gini para a renda, dos municípios capixabas - 1991 e 2000

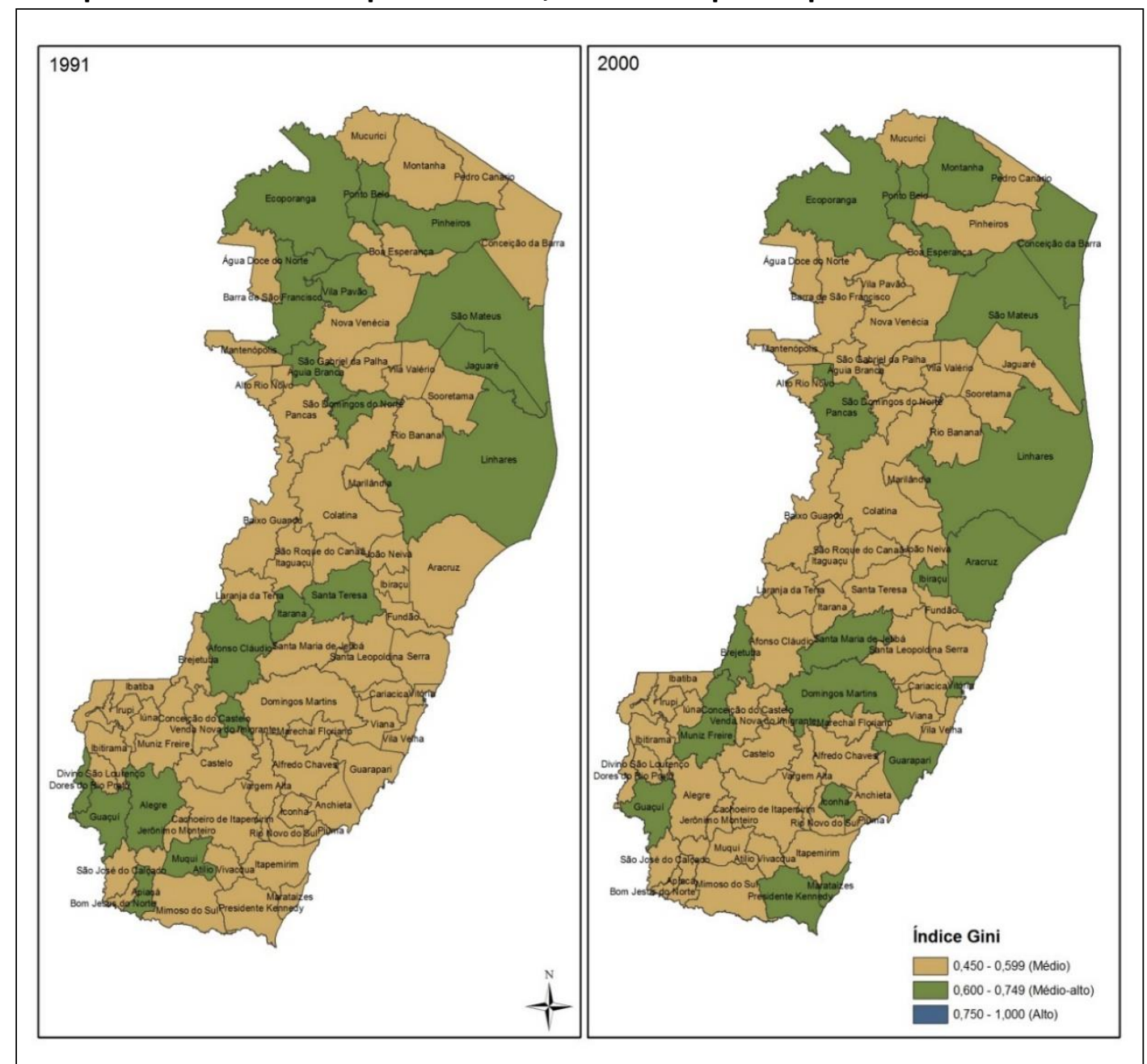

Fonte: Elaborado com dados publicados pelo PNUD (ADHB).

Conforme os Censos Demográficos de 1991 e 2000, todos os municípios se enquadravam dentro de duas faixas de grau de desigualdade, médio e médio-alto grau de concentração de rendimentos. $O$ destaque da concentração médio-alta da renda está na faixa litorânea norte, que vai do município de Aracruz até Conceição da Barra, interrompida apenas pelo município de Jaguaré. Isso pode está diretamente relacionado ao pouco dinamismo econômico, além do 
avanço da pecuária, da silvicultura e da cana-de-açúcar na região, gerando desemprego e migração para o meio urbano.

Como exposto, ocorreu maior dispersão da desigualdade no território. Apesar disso, o número de municípios que se enquadravam na categoria de concentração médio-alto quase não se alterou, passando de 19, em 1991, para 20, em 2000. Contudo, o aumento da desigualdade nos municípios mais populosos foi considerável. No início da década, os que apresentavam Índice de Gini na faixa médio-alto possuíam um contingente populacional de próximo a 454 mil habitantes, ou seja, 17,4\% da população capixaba. Em 2000, esse número passou para 934 mil pessoas, o que correspondia a $30,2 \%$ da população total.

A correlação da renda média familiar per capita (em salários mínimos) guarda uma correlação quase nula $(0,149)$ com o Índice de Gini. Uma majoração da média dos ganhos familiares não garante melhora na distribuição da renda. Assim também, a correlação entre o IDHM-R e o Índice de Gini é muito fraca: apenas 0,127. Portanto, necessário se faz a inclusão, na dimensão renda do IDHM, de um indicador capaz de mensurar as disparidades na distribuição dos rendimentos.

\section{Cálculo e análise do Índice de Desenvolvimento Humano Municipal Ajustado (IDHMA)}

De posse dos três indicadores: IDHM-R, IDHM-E e IDHM-L, mais o Índice de Gini, acrescentado na dimensão renda, construiu-se o Índice de Desenvolvimento Humano Municipal Ajustado (IDHMA). O resultado para cada município pode ser visualizado no Mapa 4.

No início da década de 90 somente os municípios de Ecoporanga, Água Doce do Norte, Pedro Canário, Conceição da Barra, Alto Rio Novo, Águia Branca, Pancas, Jaguaré - acima do rio Doce -, e Presidente Kennedy, na divisa com o Rio de Janeiro, apresentavam baixo-médio desenvolvimento humano. Apenas quatro municípios possuíam IDHMA médio-alto: Colatina, Vitória, Vila Velha e Alfredo Chaves. Os demais estavam se enquadravam na categoria médio desenvolvimento humano. 
Mapa 4 - Índice de Desenvolvimento Humano Municipal Ajustado (IDHMA) dos municípios capixabas - 1991 e 2000

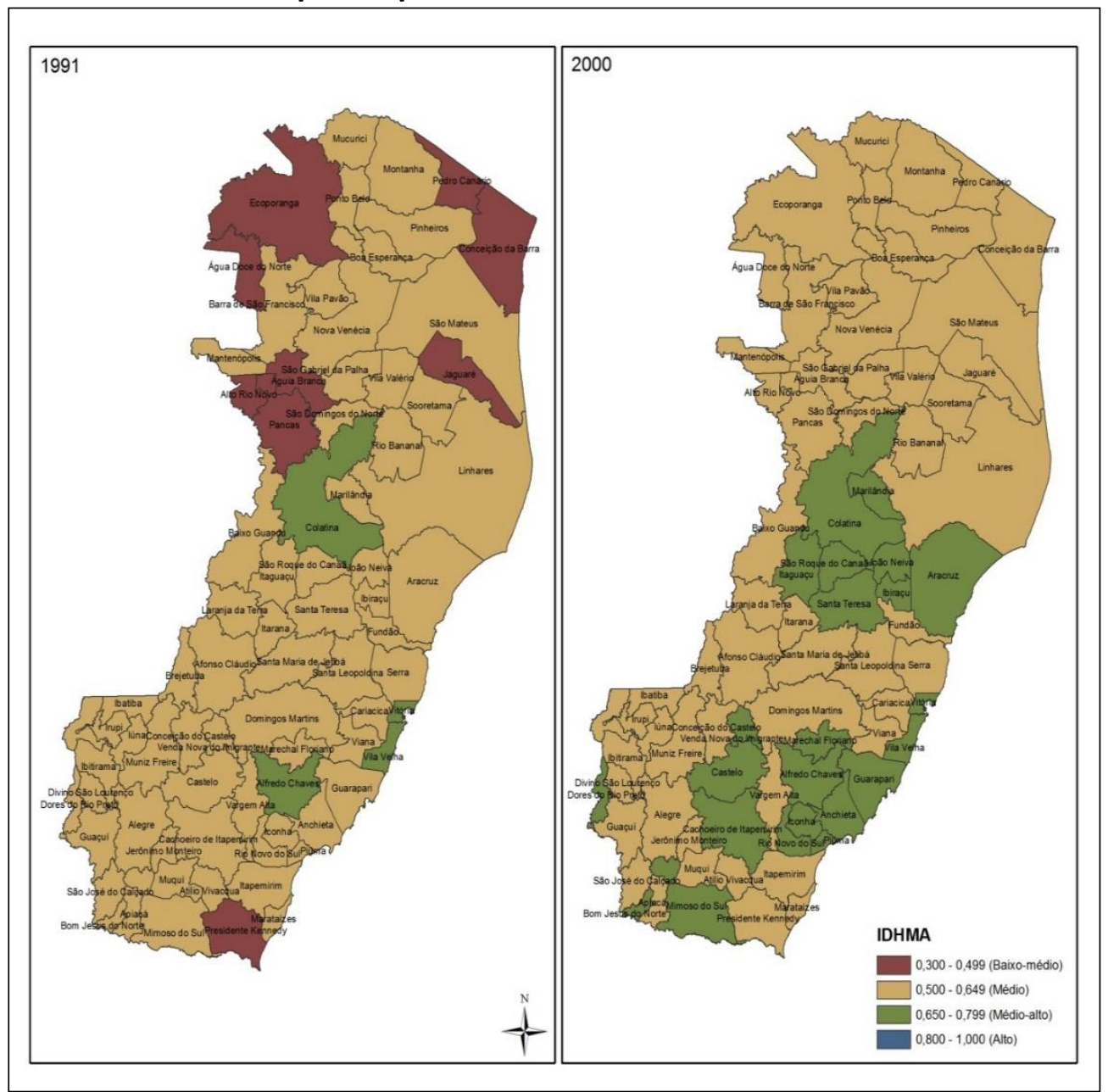

Fonte: Elaborado com os dados do IBGE e do PNUD (ADHB).

Em 2000, todos os municípios que estavam com baixo-médio desenvolvimento humano no início dos anos 90 mudaram para a faixa seguinte, ou seja, para médio desenvolvimento humano. Na categoria médio-alto desenvolvimento humano foi acrescido mais 19 municípios: a) Marilândia, Itaguaçu, São Roque do Canaã, João Neiva, Ibiraçu, Aracruz e Santa Teresa, na região polarizada por Colatina; b) Guarapari, Marechal Floriano, Anchieta, Iconha, Piúma, Rio Novo do Sul, Venda Nova do Imigrante, Castelo, Cachoeiro de Itapemirim, Mimoso do Sul, Bom Jesus do Norte e Dores do Rio Preto, na parte sul do estado. Há de se enfatizar que nenhum município do estado, em 2000, atingiu alto índice de desenvolvimento humano.

Visualmente nota-se que o norte do estado é a região com menor desenvolvimento humano. A ocupação mais forte, iniciada somente no início do século $X X$, trouxe consigo uma intensa atividade de extração madeireira. Nas terras mais quentes logo se firmou a pecuária extensiva, a qual emprega reduzida quantidade de trabalhadores. A crise na estrutura produtiva do final dos anos 50 também contribuiu no sentido de iniciar a migração campo-cidade, acelerada posteriormente não só pela erradicação de parte dos cafezais, mas também pela implementação, nas lavouras, de novas tecnologias poupadoras de mão-de-obra. Além disso, os projetos 
agroindustriais, a partir dos anos 70 , foram responsáveis pela concentração da estrutura fundiária. Destacam-se nesse âmbito, as plantações de eucaliptos para atender ao projeto fábrica-porto da Aracruz Celulose (atual Fibria) e as plantações de cana-de-açúcar, a partir dos anos 80, como fomento para as cinco destilarias: duas em Conceição da Barra, e uma nos municípios de Boa Esperança, Pedro Canário e Linhares.

Não se deve esquecer também que o setor público, especialmente o Governo Federal, concentrou investimentos na Região da Grande Vitória. Ao optar por uma política industrial em um pequeno lugar geográfico do estado, promoveu-se a intensa migração e ocupação desordenada do espaço urbano, gerando grandes problemas sociais, como violência, desemprego, falta de saneamento básico, déficit habitacional etc. Nesse sentido, municípios como Serra e Cariacica, apesar de possuírem melhor nível de industrialização e boa dinâmica do setor de comércio e serviços, possuem médio IDHMA.

A parte sul obteve aumento significativo no número dos que mudaram de categoria de desenvolvimento. Dois núcleos de municípios formados com IDHMA médio-alto formam essa região. O primeiro é composto pelas cidades de Castelo, Venda Nova do Imigrante e Cachoeiro de Itapemirim. Este, grande município polarizador econômico da região, em 2002, possuía 532 empresas de pequeno e médio porte, com destaque para o segmento de mármore e granito. Também Castelo se destaca nesse segmento.

O segundo núcleo é formado pelos municípios litorâneos de Guarapari, Anchieta e Piúma - onde o turismo é a atividade principal, seguido pelo ramo de comércio varejista - e pelos municípios de Alfredo Chaves, Rio Novo do Sul, Iconha e Marechal Floriano, reconhecidos cultivadores da bananicultura em pequenas propriedades familiares.

A união de três dimensões que representam as condições de saúde (longevidade), educação e renda encontra respaldo que a pessoa humana precisa desfrutar de uma vida longa e saudável, de meios para desenvolver suas faculdades e potencialidades, e de recursos materiais capazes de atender as suas necessidades físicas e de bem-estar. Nota-se assim, que o indicador por si só não apresenta todas as informações capazes de analisar determinado município do estado se não levarmos em consideração, por exemplo, o processo de ocupação, os fatores geográficos, as políticas governamentais e como foi a inserção de dada região no sistema econômico.

\section{Considerações finais}

O desenvolvimento humano no Espírito Santo nos anos 90 foi analisado, neste trabalho, através de um indicador final, denominado Índice de Desenvolvimento Humano Municipal Ajustado (IDHMA). Este trouxe contribuições metodológicas (nas dimensões longevidade e renda) ao Índice de Desenvolvimento Humano Municipal (IDHM), do PNUD. Além disso, como forma de auferir as desigualdades na distribuição de renda, incluiu-se o Índice de Gini.

Assim, constatou-se que a maioria dos municípios capixabas estavam na faixa de médio desenvolvimento humano, e nenhum se encontravam na categoria alto desenvolvimento. Destacam-se núcleos de municípios com médio-alto desenvolvimento humano: um núcleo 
gravitado pelo município de Colatina; o outro pelo município de Cachoeiro de Itapemirim, que interliga com os municípios da zona litorânea iniciada na Capital e finalizada em Piúma.

Observou-se ainda, tanto em 1991 como em 2000, que os municípios da parte norte do estado possuíam os piores níveis nesse indicador. Isso se deu como reflexo das particularidades de ocupação do solo e da evolução socioeconômica da região.

Verificou-se também, que os municípios como Serra e Cariacica, apesar de pertencerem à Grande Vitória e possuírem um setor industrial mais estruturado, e uma cadeia de serviços e comércio significativa, seus indicadores estavam na categoria médio desenvolvimento humano. Isso pode ser atribuído, além de outros fatores, a uma gama de problemas advindos pelo inchaço do meio urbano, pela má distribuição dos rendimentos e pela incapacidade do setor público lidar com tais dificuldades.

\section{Referências}

ATLAS DO DESENVOLVIMENTO HUMANO NO BRASIL (ADHB). Versão 1.0.0. ESM Consultoria, c2003. PNUD, 2003.

BANCO CENTRAL DO BRASIL (BCB). Correção de valores. Ministério da Fazenda. Disponível em:< http://www4.bcb.gov.br/?CORRECAO>. Acesso em: 6 nov. 2017.

D. SACHS, Jeffrey; LARRAIN B., Felipe. Macroeconomia: em uma economia global. revis. e atual. São Paulo: Makron books, 2000. p.306-346.

INSTITUTO BRASILEIRO DE GEOGRAFIA E ESTATÍSTICA (IBGE). Censo demográfico: famílias e domicílios. IX Recenseamento Geral do Brasil - 1980. Rio de Janeiro: IBGE, 1983. v.1, t.6, n.17. Espírito santo.

. Censo demográfico: famílias e domicílios. Censo demográfico 1991. Rio de Janeiro: IBGE, 1996. n.19. Espírito santo.

. Censo demográfico: famílias e domicílios. Censo demográfico 2000. Disponível em:<http://www.biblioteca.ibge.gov.br>. Acesso em: 05 abril 2017.

. Pesquisa industrial anual. Banco de dados agregados (SIDRA) de 1990 e 2000.

Disponível em: <http://www.sidra.ibge.gov.br/bda/pesquisas/pia/default.asp>. Acesso em: 03 agosto 2017.

INSTITUTO DE PESQUISA ECONÔMICA APLICADA (IPEA). Base de dados. Disponível em: <http://www.ipeadata.gov.br>. Acesso em: 19 maio 2017.

POPULATION REFERENCE BUREAU (PRB). 2001: Cuadro de la población mundial del Population Reference Bureau. Datos y cálculos demográficos sobre los países y regiones del mundo. Edición en folleto, 2001. 
PROGRAMA DAS NAÇÕES UNIDAS PARA O DESENVOLVIMENTO (PNUD). Entenda o cálculo do IDH Municipal (IDHM) e saiba quais os indicadores usados. Disponível em:

<http://www.pnud.org.br/atlas/PR/Calculo_IDH.doc>. Acesso em: 01 set. 2008.

. Entenda os indicadores. Disponível em: <http://www.pnud.org.br/ indicadores/>. Acesso em: 03 set. 2008.

. Relatório sobre o desenvolvimento humano no Brasil 1996. Rio de janeiro: IPEA, 1996.

(b). Relatório do desenvolvimento humano 1996. Lisboa: Tricontinental, 1996.

. Relatório do desenvolvimento humano 2002. Portugal: SIG, 2002.

ROLIN, Cássio. Um índice de pobreza humana municipal para o Brasil. 2005. 25p. Disponível em:< http://www.economia.ufpr.br/publica/textos/2005/Cassio\%20 Rolim.pdf>. Acesso em: 28 ago. 2008.

SANDRONI, Paulo. Dicionário de economia do século XXI. Rio de Janeiro: Record, 2005.

SANTOS, Moisés P. dos. Uma proposta de melhoria do Índice de Desenvolvimento Humano Municipal a partir do caso do estado de São Paulo. Revista Ecco. São Paulo, ano 1, n. 1, 2006. 